\title{
From Nottingham to Nijmegen
}

The next 12 months will see important changes in the Annals. From 1 July the editorial office moved to Nijmegen under the editorship of Leo van de Putte, and from January 2000 the Annals will become the official journal of EULAR though still retaining its half century old title Annals of the Rheumatic Diseases. Leo is exceptionally well qualified for the position of editor. He is an internationally respected researcher, he is the immediate past president of EULAR, and has been an active member of the Annals editorial board for seven years. Adoption of the journal by EULAR is also appropriate. The Annals is arguably the top ranking rheumatology journal in Europe and has the expert backup of the BMJ editorial and publishing teams to ensure quality and professionalism. The journal already has a cosmopolitan international editorial board and two of three associate editors from mainland Europe. Furthermore the Annals has no national rheumatology society affiliation. Under the leadership of Leo van de Putte and his new board it is envisaged that the Annals will continue to grow in stature to become one of the leading rheumatology journals for original research and continuing specialist education.

As retiring editor I would like to pay tribute to the board members, associate editors, editorial assistant, technical editors, commissioning and marketing assistants, and editorial staff of the BMJ who have served the Annals so well during the period 1992-99. Throughout this time we have recognised our responsibilities both to submitting authors (who expect efficient, courteous and professional processing of their work) and to subscribers (who wish to read high quality, relevant original papers, topical editorials and stimulating educational series). It is a large team and all must take credit for the innovations and changes that have been made to enhance the quality of the Annals. Of particular importance are the following:

- improved efficiency and quality of peer review and the service to submitting authors

- consistently rapid acceptance to publication time

- annual publication of specific editorial objectives and performance (Annals remains the only rheumatology journal to do this)

- appointment of an active editorial board with trainee representation and the youngest known mean age for any rheumatology journal

- appointment of a regular statistical adviser

- clear guidelines regarding editorial concern and policy on redundant publication ${ }^{1}$

- founder member of the Rheumatology Journal Editors Group to agree uniform systems of referencing ${ }^{2}$ and acronyms $s^{3}$ in rheumatology journals, and the adoption of the CONSORT system ${ }^{4}$ for reporting randomised controlled trials

- removal of a case report section (for reasons see Doherty ${ }^{5}$ )

- introduction of the educational series Lesson of the Month

- introduction of Case studies in Diagnostic Imaging

- use of educational "fillers" such as Rheumatological Stamp and Unusual and Memorable

- utilisation of BMJ guidelines in determining supplement selection, and the incorporation of peer reviewed supplements within monthly issues rather than as separate publications

- reduced, and subsequently free, trainee subscription rates

- introduction of attractive format, including a back cover index and a varying front cover illustration to individualise issues

- availability of Annals on the internet, combined with innovative search potential ${ }^{6}$

- abolition of commercial advertising from the journal (from January 1998 for the period of the current editorial board)

- attainment of the status of the official journal of EULAR Further development and continuing evolution of the Annals is clearly necessary, especially as the journal takes on an even more major role in Continuing Medical Educational (CME) for European rheumatologists.

Finally, on behalf of the whole editorial board I would like to thank the expert reviewers who have given so much of their time to ensure the quality of the peer review process. We are, of course, equally indebted to all our contributors, without whom the journal simply would not exist. The whole board and the BMJ editorial staff wish Leo van de Putte and the new team every success in taking the Annals with pride into the next millennium.

MICHAEL DOHERTY

Academic Rheumatology, Clinical Sciences Building, City Hospital, Nottingham NG5 $1 P B$

1 Doherty M. The misconduct of redundant publication. Ann Rheum Dis 1996:55:783-5.

2 Doherty $M$, Arend W. A uniform reference system for rheumatology journals. Arthritis Rheum 1997;40:199.

3 Bombardieri S, Caponi L, Arend WP. A unified list of acronyms for the rheumatology literature. Arthritis Rheum 1998;11:1901-5.

4 Doherty M. Uniform structured formats for scientific communicationshow far should we go? Ann Rheum Dis 1997;56:81-2.

5 Doherty M. What value case reports? Ann Rheum Dis 1994;53:1-2.

6 Doherty M. The birth of eARD. Ann Rheum Dis 1999;57:197. 


\section{Changing of the guard}

From 1 July there will be a changing of the guard. A new editorial team starts and the editorial office moves from Nottingham to Nijmegen. The new crew takes up a considerable challenge. Mike Doherty and his team have done an excellent job in making the Annals of the Rheumatic Diseases a leading journal in its field: a recognisable, readable journal of high scientific and educational standard. It also is an amazingly efficient journal with a rapid acceptance to publication time. They are to be congratulated on this outstanding performance.

The most important goal of the Annals has always been to support the readership in its profession in the broadest sense, and this aim will remain. This means a journal of high scientific and educational standards that is at the same time attractive to the readership. Also, a journal that remains sensitive to what happens in society, in general, and in patient organisations, in particular, and that would like to be recognised as the voice of the professional, scientific, and educational community. The unique characteristic of the "discipline of medicine" is its heterogeneity, comprising a vast array of different fields from molecular biology, genetics, and immunology to, for instance, social medicine and health care economics. An inevitable consequence of this diversity is a lack of understanding between subspecialties because of different jargons and subcultures. One way to overcome or reduce this problem is careful editing. The editor and his team recognise this important issue.

From January 2000 the Annals will be the official journal of the European League Against Rheumatism, EULAR. Both EULAR and the Annals are to be congratulated on this liaison. From the year 2000 there will be annual EULAR congresses, and educational activities within the organisation will certainly increase. The Annals will reflect and disseminate these activities appropriately.

The new team gratefully recognises the achievements of Mike Doherty and his coworkers, who have done so well, and also of Colin Barnes, who with great skill and persistence edited EULAR's educational journal Rheumatology in Europe, which will now merge with the Annals.

The new team would like to continue a great Nottingham tradition and add new elements to it. They hope to please the readership with a fascinating journey through the ever changing fields of science and education in rheumatology.

Editor 